\title{
Sobre o viver em uma cidade capacitista: antes, durante e depois da pandemia da COVID-19
}

\author{
On living in an ableist city: \\ before, during and after the COVID-19 pandemic
}

Annibal Coelho de Amorim (https://orcid.org/0000-0003-0157-4527) ${ }^{1}$

Sônia Regina da Cunha Barreto Gertner (https://orcid.org/0000-0003-3564-5039) ${ }^{2}$

Laís Silveira Costa (https://orcid.org/0000-0001-6089-7129) ${ }^{3}$

Anna Paula Feminella (https://orcid.org/0000-0003-0693-3517) ${ }^{4}$

\footnotetext{
${ }^{1}$ Programa IdeiaSUS, Gabinete da Presidência, Fundação Oswaldo Cruz. Av. Brasil 4365 Manguinhos, 21040-900. Rio de Janeiro RJ Brasil. annibalamorim. fiocruz@gmail.com

${ }^{2}$ Coordenação-Geral de Gestão de Pessoas, Presidência da Fiocruz, Fundação Oswaldo Cruz. Rio de Janeiro RJ Brasil. ${ }^{3}$ Departamento de Administração e Planejamento em Saúde, Escola Nacional de Saúde Publica Sergio Arouca, Fundação Oswaldo Cruz. Rio de Janeiro RJ Brasil. ${ }^{4}$ Escola Nacional de Administração Pública. Brasilia DF Brasil.
}

\begin{abstract}
The images of cities before, during and after the COVID-19 pandemic represent a contemporary challenge. During this period, thinking about being a person, being there and living in an ableist city/society brings to light the loss of rights and the demands of population segments, particularly in the face of architectural, communicational, attitudinal, sensory and sociocultural barriers. To thematize about experiencing the different types of daily inaccessibility in the cities come into contact with and raise discussions about the ethical-aesthetic level of the existential territories of people with disabilities and mental suffering. To what extent do urban planners maintain concepts that support invisibility constructs, which reflect segregations generated by macropoliti$c s$ ? Would they be imagining the cities without thinking about the people who inhabit them? The present essay collaborates with the debate on the need for actions aimed at overcoming capacitism. Based on critical science theories and the concept of the health subject's right, the "topic landscape" is explored with a view to implementing accessible and inclusive public policies.
\end{abstract}

Key words Disability, Disabled persons, COVID-19, Normativity
Resumo As imagens das cidades antes, durante e depois da pandemia de COVID-19 representam um desafio contemporâneo. Nesse periodo, pensar sobre o ser, o estar e o habitar em uma cidadel sociedade capacitista traz à tona a perda de direitos e as demandas de segmentos populacionais particularmente diante das barreiras arquitetônicas, comunicacionais, atitudinais, sensoriais e socioculturais. Tematizar sobre o viver as diferentes inacessibilidades cotidianas nas cidades tangenciam e suscitam discussões no plano ético-estético dos territórios existenciais das pessoas com deficiência e sofrimento psíquico. Em que medida, urbanistas mantém conceitos que sustentam constructos de invisibilidade, que refletem segregações geradas pela macropolítica? Estariam pensando as cidades sem pensar nas pessoas que nelas habitam? O ensaio colabora com o debate sobre a necessidade de ações que visam superar o capacitismo. Partindo de teorias das ciências críticas e da noção de direito do sujeito sanitário, sobrevoa-se a "paisagem do tema" com vistas à efetivação de politicas públicas acessiveis e inclusivas.

Palavras-chave Deficiência, Pessoas com deficiência, COVID-19, Normatividade 


\section{Introdução}

A análise sobre ser, estar, habitar, ganha contornos dramáticos quando além da pandemia da COVID-19 e suas implicações sanitárias, sobrepõe-se temas ligados ao planejamento urbano.

Impactos pandêmicos se fizeram sentir em diferentes segmentos populacionais, particularmente entre os que habitam em territórios vulnerabilizados, notadamente pessoas com deficiências e/ou sofrimento psíquico.

Individual ou coletivamente, estes segmentos se insurgem contra diversas barreiras socioculturais (das arquitetônicas às atitudinais), verdadeiros obstáculos à expansão de territórios existenciais, que segundo Borges ${ }^{1}$ se caracterizam por suas dimensões ético-estéticas na saúde coletiva.

Nesse sentido, referindo-se à pandemia da COVID-19, Medeiros e Rajs ${ }^{2}$ ressaltam:

[...] A realidade tem mostrado que os riscos e efeitos catastróficos da doença são desproporcionalmente maiores para as populações vulnerabilizadas, em especial as que vivem em assentamentos informais, favelas, loteamentos, ocupações, bem como a população em situação de rua [...] (p. 6)

Que lições acerca da vida das pessoas com deficiência e/ou sofrimento psíquico foram assimiladas no contexto da pandemia?

Nesse sentido, refletir sobre o viver em uma cidade/sociedade capacitista - capacitismo (do inglês ableism), termo segundo o qual a deficiência, é vista como algo a ser superado ou corrigido" na sociedade contemporânea - inclui tanto a opressão ativa e deliberada quanto a opressão passiva, remete à discussão das condições da acessibilidade em favelas e periferias, direitos sem os quais o viver transforma-se em abstração nos territórios existenciais, a que Borges ${ }^{1}$ refere como:

[...] toda criação conceitual é histórica, contextual e singular, sempre uma singularidade [...] a teoria é a porta de acesso ao engajamento politico em um mundo cognoscivel, compartilhando territórios existenciais que não se limitem ao 'sobrevoo conceitual' sobre a realidade investigada[...] (p. 108).

$\mathrm{O}$ ensaio reflete sobre como o viver em cidades capacitistas hostiliza a existência de pessoas com deficiência, segmento que segundo a ONU representa cerca de $15 \%$ da população mundial. Se a UPIAS ${ }^{3}$ - Union of the Physically Impaired Against Segregation (1975) considera a deficiência opressão social, o que dizer da arquitetura das cidades contemporâneas? As cidades oprimem pessoas com deficiência e ou sofrimento psíquico porque a maioria expressiva dos dispositivos so- cioculturais (como museus, cinemas, teatros etc) mantêm visão estreita a partir de uma perspectiva segregacionista.

Ao considerar a "deficiência" como "produção social", ressalta Kipen ${ }^{4}$ que "[...] a imagem de completude, de corpo completo, inventa um espelho deformado do corpo incompleto, anormal, inadequado [...] a produção do corpo normal, [...]” (p. 129), acaba por influir na concepção moderna de cidades e seus dispositivos sociais e culturais.

Assim, ao serem analisadas as cidades/sociedades recaem sobre estas a falta de políticas públicas voltadas às pessoas, em que a equidade se faça presente, garantindo respeito aos direitos insurgentes ${ }^{5,6}$ dos sujeitos que nelas habitam. Segundo Santos ${ }^{5}$ :

[...] nunca como hoje foi importante não desperdiçar ideias e práticas de resistência. Significa apenas que só reconhecendo as debilidades reais dos direitos humanos é possivel construir a partir deles, mas também para além deles, ideias e práticas fortes de resistência. Esta reconstrução vai permitir que os direitos humanos se tornem um instrumento de luta, resistência e alternativa, ainda que limitado [...] (p. 104)

Nesse contexto, a questão dos direitos de segmentos populacionais discriminados (como as pessoas com deficiência e/ou sofrimento psíquico) não deve ser apartada da análise da globalização e as "consequências humanas", como proposta por Bauman ${ }^{7}$ considerada a dimensão da desterritorialização, neste ensaio a partir de uma base ético-estética existencial na saúde coletiva.

Desta forma, depreende-se que as reflexões "sobre o viver em uma cidade capacitista: antes, durante e depois da pandemia", título do ensaio, não devem ser apartadas dos preceitos que fundamentam a condição de sujeito de direito sanitário.

\section{Pessoas com deficiência/sofrimento psíquico e os impactos do capacitismo estrutural}

Cotidianamente pessoas com deficiência e/ ou sofrimento psíquico enfrentam barreiras que lhes inviabilizam o exercício dos seus direitos fundamentais. É como se a sociedade lhes dissessem “não".

A arquitetura opressiva nos espaços públicos, o tratamento compassivo ou a indiferença são formas capacitistas que inviabilizam o pertencimento das pessoas com deficiência e ou sofrimento psíquico como integrantes da sociedade como sujeitos de direitos. 
No entanto, na perspectiva dos direitos humanos, os estudos contemporâneos sobre a "deficiência” nos induzem a concluir que é o seu corpo "defeituoso"/ "anormal" que lhe limita a existência $^{8}$, desresponsabilizando a sociedade e o capacitismo estrutural societário. Segundo o autor, as experiências capacitistas modulam os indivíduos e ampliam a dissonância diante a normatividade dos corpos, causando fissuras nas expectativas das interações pessoais, reafirmando de forma não silenciosa as diferenças.

Ribeiro e Baptista ${ }^{9}$, em artigo instigante, propõem reflexão acerca da compreensão dos "paradoxos da produção da diferença no contemporâneo", abordam os "ruídos e os silêncios de um corpo na cidade", particularmente aqueles relacionados ao princípio da alteridade de corpos silenciados ou invisíveis que circulam nas cidades "modernas". Nas palavras dos autores, apoiados em Caiafa ${ }^{10}$ :

[...] As cidades geram um poderoso espaço de exterioridade que se opõe e tanto ao interior dos espaços fechados quanto à interioridade do sujeito. A heterogeneidade ali ativa dispersa focos de identidade e as recorrências do familiar, introduzindo, portanto, variação nos processos subjetivos [...] (p. 92).

Segundo Adriana Dias" "capacitismo é a concepção presente no social que lê as pessoas com deficiência como não iguais, menos aptas ou não capazes para gerir a próprias vidas" (p. 2), e que segundo Campbell ${ }^{12}$ (p. 44), define-se como: "uma rede de crenças, processos e práticas que produz um tipo particular de compreensão de si e do corpo (padrão corporal), projetando padrão típico da espécie e, portanto, essencial e totalmente humano". A deficiência para o capacitista, segundo Dias, "é um estado diminuído do ser humano", ou sob a lógica foucaultiana ${ }^{13}$ do "falar" em que a condição de sujeito é reduzida a objeto sob a lupa do biopoder, uma vez que palavras:

[...] que significam as coisas se chamam nomes substantivos, como terra, sol. Aquelas que significam os modos, marcando ao mesmo tempo o sujeito ao qual se convêm se chamam adjetivos, como bom, justo, redondo [...] Entre a articulação da linguagem e da representação há, contudo, um jogo [...] (Foucault 1995, p. 114)

Esse jogo de representações reserva espaço particular para a linguagem do déficit ${ }^{14}$ que, continuamente reificada, inunda a cultura com expressões capacitistas. Foucault ${ }^{15}$, em defesa da sociedade, destaca a perspectiva da "insurreição dos saberes contra a instituição de poder do discurso científico" (p. 19).
Assim, os impasses decorrentes das inacessibilidades cotidianas, a naturalização da corponormatividade, decorrente da visão idealizada do ser humano - reitera a ideia de isolamento que, nesse sentido, é muito anterior à pandemia -, constituindo-se em "caldo existencial" de quem sobrevive com deficiência e/ou sofrimento psíquico em ambientes opressivos da urbe.

Em contraposição a esta postura segregacionista, é nas cidades que as políticas públicas equitativas chegam, ou, pelo menos, deveriam chegar. Portanto, coerente com os argumentos ensaísticos, postula-se que as necessidades das pessoas com deficiência/ou sofrimento psíquico não podem ser negadas a partir de premissas capacitistas, que desconhecem os direitos de sujeitos sanitários. É contestável que o urbanismo das cidades seja feito a partir de um olhar enviesado em que percentuais estatísticos (por exemplo, de pessoas com deficiência), definem o modus operandi que discriminam projetos habitacionais adequados às especificidades de sujeitos de direitos sanitários.

Ao esclarecer o conceito acima, Vasconcellos e Oliveira ${ }^{16}$ reafirmam que:

[...] o papel do cidadão, longe de ser mero cumpridor de ações ditadas por técnicos e autoridades públicas, é também o de um 'sujeito sanitário', crítico e corresponsável pelo processo coletivo de construção da saúde [...] (p. 16)

Desta forma, os autores ${ }^{16}$ destacam que a expressão ‘sujeito sanitário' trata de migração paradigmática, transformação de alguém tido como mero objeto das políticas (de saúde, trabalho, habitação), para outro alguém, sujeito ativo, formulador e fiscalizador de seus- direitos (grifo dos autores).

Ao sobrepor os limites da relação sujeito de direito sanitário para além do campo da saúde, identifica-se que as perspectivas sobre ser, estar, habitar em uma cidade depende de engajamento individual e coletivo dos sujeitos, contrapondose ao capacitismo inerente à condição humana na vida social.

Logo, este ensaio, convoca que de um sobrevoo da "paisagem das cidades" se derive para a "paisagem temática", da pessoa com deficiência ou sofrimento psíquico, partindo de teorias das ciências críticas e da noção de direito do sujeito sanitário. O estímulo do pensar, pela via Homo Faber sennettiana ${ }^{17}$, estabelece uma espécie de "tour" em que as cidades capacitistas não resultem apenas da produção acadêmica, mas talvez de uma perspectiva "artivista” poética e político-estética. Este "sobrevoo temático", todavia, pode se dar a partir de performances artístico- 
culturais (instalações em museus, festivais, canções populares, poesias) que se contraponham a simbologia capacitista, que de forma sutil ou não, se espraia na cultura quando a linguagem do déficit $^{18}$ do biopoder, reduzem sujeitos a objetos da narrativa corponormativa.

Como exemplo de uma perspectiva anticapacitista, o ensaio serve-se de um fragmento da poesia de Carmen Vallejo ${ }^{19}$, que denuncia o que as pessoas com deficiência vivenciam:

[...] Mi cuerpo ME sirve a mí. Para sanarme. $Y$ sanar con las mías. Algo para lo que la sociedad de fuera,esa que nos nombra discapacitadas nunca ha sido capaz ni ha servido de nada [...]

Assim, além do enfrentamento anticapacitista de ultrapassar barreiras do modelo produtivo de sociedade, busca-se afirmar o locus da existência da singularidade do direito do sujeito enquanto uma práxis política cotidiana.

Frente ao apagamento da marca existencial das pessoas diferentes no processo societário, torna-se crucial desconstruir a ideia de "incompletude e anormalidade" dos corpos, e servir-se das teorias retratadas no documentário "Crip Camp" ${ }^{20}$ que, na condição de "espelhos" da realidade, revelam que incompletas são as cidades/ sociedades capacitistas.

\section{Diante da necropolítica pandêmica como enfrentar retrocessos no campo dos direitos humanos?}

Em passado recente foram estabelecidas respostas contra-hegemônicas de natureza anti-asilar. A supressão de verbas destinadas a internação de longa permanência, reorientaram o processo assistencial, opondo-se à segregação social, (re) integrando pessoas fora do espaço hospitalar. Originam-se Centros de Atenção Psicossocial (CAPS) e residências terapêuticas, incluindo no corpus social - a civitas sennettiana ${ }^{17}$ - pessoas historicamente excluídas que passam a fazer parte da paisagem, podendo ser, estar, habitar a cidade. Da mesma forma, a Convenção Internacional sobre Direitos das Pessoas com Deficiência ${ }^{21}$ tem seu texto aprovado pela Assembleia Geral das Nações Unidas em 13 de dezembro de 2006, sendo promulgado pelo Brasil em 25 de agosto de 2009, através do Decreto no ${ }^{\circ} 6.949$, sendo implementado como emenda constitucional. Outro documento considerado um novo marco civilizatório nas relações societárias, partindo da premissa do conceito de sujeito de direitos sanitários, abordado anteriormente, é a Lei Brasileira de Inclusão da Pessoa com Deficiência ${ }^{22}$ (LBI /
Lei no 13.146, de 06/07/2015). A LBI é também conhecida como Estatuto da Pessoa com Deficiência, em seu art. $4^{\circ}$ estabelece que "toda pessoa com deficiência tem direito à igualdade de oportunidades com as demais pessoas, e não sofrerá nenhuma espécie de discriminação em razão de sua condição" (p. 22).

Gertner e Vasconcellos ${ }^{23}$, evocam direitos das pessoas com deficiência consagrados nestes dois documentos, como no art. 11 da Convenção que se estabelece que os Estados Partes "tomarão todas as medidas necessárias para assegurar a proteção e a segurança de pessoas com deficiência que se encontrarem em situações de risco", inclusive em emergências humanitárias.

Contudo, ao tempo em que este ensaio é escrito e se registra a pandemia da COVID-19, medidas anacrônicas buscam reestabelecer retrocessos político-ideológicos, como o Dec. 10.502/2020, cuja proposição busca reinstituir a Política Nacional de Educação Especial, retomando práticas segregadoras que já se mostraram ineficazes e até inconstitucionais. Tais práticas reinstituem a lógica da marginalização de pessoas com sofrimento psíquico e/ou pessoas com deficiência, semelhantes ao caráter asilar de triste memória na história da Saúde Mental. Viola, ainda, o direito de todos viverem em uma sociedade plural e diversa, sem discriminações de quaisquer natureza. Embora o citado decreto esteja suspenso aguardando julgamento no Supremo Tribunal Federal por Ação de Inconstitucionalidade (ADI) 6590, a insistência de forças conservadoras de cunho segregacionista permanecem e se apresentam como risco num tempo em que a necropolítica é exaltada e praticada nestes tempos sombrios da política nacional.

Assim, este ensaio busca destacar, por um lado, a desconstrução crítico-prática do modelo que reproduz práticas de perfil asilar, como no caso da lógica manicomial. Desta forma, ao avançar na compreensão socioantropológica sennettiana, da relação "carne versus pedra” abordada por Duarte ${ }^{17}$, reinstitui-se a lógica dos direitos da população, tematizada na perspectiva do viver segundo laços de bases territoriais da existência humana. Segundo o autor ${ }^{17}$ :

[...] esse processo é constitutivo da sociedade democrática e plural, na medida em que essa também visa estabelecer canais de sociabilidade entre os diferentes; no entanto, proteger a diversidade na intimidade, sem promover a integração das diferenças, torna a primeira tarefa inócua [...] (p. 57-58)

Aproximando-se do "itinerário da crítica social de Richard Sennett", Duarte ${ }^{17}$ ressalte-se 
ainda que a dinâmica referida é considerada por Sennett como parte das "tiranias da intimidade". Nas palavras de Duarte esse tipo de tirania:

[...] remete ao ato de desconsiderar a existência e necessidades do outro - uma espécie de 'individualismo possessivo recíproco', que termina por prejudicar as condições para a cooperação e convívio social. Dá-se origem a uma ideologia da intimidade: os males sociais seriam derivados da impessoalidade, da alienação e da frieza - a solução passaria pelo resgate da privacidade /intimidade. Mas é nela que se consubstancia o isolamento do sujeito [...] (p. 58).

Segundo Duarte, analisando a polis moderna, Sennett refere que a cidade - pós-revolução francesa - aspirava "criar um espaço de liberdade no qual o ir e vir não encontrassem barreiras, mas na prática terminou por gerar espaços urbanos vazios ou de passagem, os não lugares [...]” (p. 58).

E conclui ${ }^{17}$ :

[...] sem o civitas, ela perde sua instância de articulação social e se transforma numa conjunção amorfa de espaços e corpos que não se comunicam [...] Sennett irá constatar que a vida as grandes cidades 'socializa o espaço', mas promove o individualismo e silencia as práticas corporais com sua ênfase na mobilidade [...] (p.59).

\section{Pessoas como textos \& cidades como um corpo social}

Este ensaio serve-se de Gergen ${ }^{24}$ ao utilizar a metáfora de pessoas como "textos", o que direciona a linha argumentativa de que "variados textos" habitam em permanente "leitura/releitura" uns dos Outros. Tomando emprestado essa metáfora gergeniana, assume-se que as "cidades" representam espaço em que os textos podem se encontrar incluídos em livros, que a rigor devem compor o grande acervo "bibliotecário" do corpo social. Interroga-se, pois, quem no "corpo social", à priori, exerce um poder de censurar a presença de pessoas como textos (com deficiência e/ou sofrimento psíquico) como provas de territórios existenciais diferenciados? Interroga-se também que "valores editoriais" têm regido as relações “intertextuais” estabelecidas em sociedade? Como o conhecimento de causa de pessoas com deficiência ou sofrimento psíquico contribuem para a transformação de "cidades/sociedades" de perfil capacitista?

É, pois, impossível negar que no III Milênio permanece o caráter de invisibilidade de "pessoas como texto", ora estigmatizadas como "deficientes", "loucas", “autistas”, aprioristicamente censu- radas existencialmente em cidades e na sociedade em geral. Este processo resulta da difusão na cultura de terminologias encontradas no DSM 5, enclausurando-as em taxonomias do déficit de caráter essencialista ${ }^{14,18,25,26}$, muitas das quais retroalimentam os valores capacitistas utilizados contemporaneamente. Grande parte dessa "censura biográfica” decorre da atuação do complexo-médico-acadêmico-industrial ${ }^{27,28}$ (CMAI), ao transformar sujeitos de direitos em objetos do discurso, tornando a cultura progressivamente enferma. Neste sentido, territórios existenciais ético-estéticos de pessoas rotuladas como "doentes mentais", "deficientes", tem suas intertextualidades sociais e culturais invisibilizadas. Blikstein $^{29}$, de maneira tácita, demonstrou que em "corredores semânticos" da linguagem fabricada são encontradas valências positivas ou negativas, que determinam marcas simbólicas nas existências de pessoas descritas por constructos sociais da linguagem do déficit.

Portanto, torna-se essencial que "pessoas como texto" busquem materializar formas insurgentes de se opor a este tipo de injustiça epistêmica, transformando o "não lugar" atribuído pelo poder biocapacitista em um "lugar de (re) existência" política, viabilizando a defesa dos seus direitos, como perspectiva da diversidade da condição humana, a que Lukács ${ }^{30}$ refere ser a base da ontologia do ser social.

De uma postura anarqueológica ${ }^{31}$, devem resultar as poesias e os manifestos anticapacitistas que devem ser "lidos de dentro para fora", como parte do acervo onde todos são, estão e habitam cidades, traduzindo fielmente o retrato pluriversificado da sociedade, rompendo a corponormatividade - imposta de fora, que censura "textos considerados imperfeitos".

Narrativas biográficas do self, na qualidade de "pessoas como textos" compõe o "corpus" social, que sob a forma de insurgência contra a invisibilidade, reafirma a diversidade inerente à condição humana

A isso Avelino ${ }^{31}$, baseado no pensamento político de Foucault, chama de produção de subjetividade. Abandona-se, pois, a "marca do destino" assume-se a demarcação de novo território existencial ético-estético na Saúde Coletiva.

Este ensaio questiona o "modus operandi" da sociedade moderna formulado a partir da lógica corponormativa em que "pessoas são consideradas como normais/perfeitas”. Assim, ao se deparar com sociedade de perfil segregacionista/ capacitista, compreende-se que esta última modela dispositivos políticos, negando territórios 
existenciais ético-estéticos de pessoas e suas singularidades. Negar a existência de pessoas com singularidades, dá passagem a "ruídos silenciados", como assinalam Ribeiro e Baptista".

Tal qual Judith Heumann ${ }^{20,32}$ preconiza, o ensaio questiona barreiras atitudinais societárias que estigmatizam, fazendo da cidade (repletas de "livros" a serem lidos) lugar para "corpos idealmente perfeitos". Na cidade partida "textos censurados" continuam a viver excluídos em "guetos", sem acesso a espaços que não respeitam suas singularidades.

\section{A primeira pessoa do singular e a primeira do plural no corpo societário}

Fragilizada em meio à pandemia, a ontologia do ser social ${ }^{30}$ acaba restringindo as trocas intersubjetivas e o pertencimento ao corpo social, deslocando as existências territoriais da primeira pessoa do plural (NÓS) à primeira pessoa do singular (EU), o que, em grande parte, reforça a "tirania da individualidade" sennetiana, obstaculizando o "artivismo" e a insurgência coletiva, tão necessárias às pessoas com deficiência e/ou sofrimento psíquico.

Mas isso não se dá de forma isolada, nem tampouco fora de um contexto político mais abrangente.

Cabe ressaltar que a invisibilidade sócio-histórica, as lacunas político-assistenciais e a perda de direitos resultam dos avanços do (ultra)neoliberalismo na América Latina ${ }^{33}$. Nesse contexto, a deficiência é um sinônimo da opressão social e a corponormatividade, tanto quanto o sofrimento psíquico, reitera a patologização do cotidiano, segregando e excluindo as pessoas que diferem da norma. Do ponto de vista prático, uma sociedade cujas estruturas neoliberais calcam-se no individualismo e meritocracia, não deixam margem para outra postura coletiva que não seja o da insurgência, opondo-se as concessões de perfil caritativo-religiosas. Em contexto de perfil conservador, o pensamento político de Michel Foucaul ${ }^{31}$ redireciona a postura individualista clássica para o posicionamento de perfil coletivista dos movimentos sociais organizados. Que alternativa se oferece que não a da militância? O coletivo deve impor suas bandeiras de luta sobre o viver na sociedade, onde o ser, o estar e o habitar deve transcender o espaço (geo)físico, como postula Bachelard.

A ausência de políticas públicas com postura anticapacitista aponta para conjunto temático mais abrangente na perspectiva interseccional e da microfísica do poder ${ }^{34}$. Assim, na civitas tão almejada por Sennett ${ }^{17}$, cada ser social conta como parte da cidadania, assumindo que a cidade incompleta e imperfeita contribui para que lacunas políticas sejam observadas, particularmente para aqueles que se encontram marcados pela diferença ("deficiência", "loucura"), em sociedade idealizada pela perfeição de inspiração secular.

Corroboramos o pensamento político de Saul Newman ${ }^{35}$ ao admitir que, "se o poder está em toda parte, se ele é coextensivo às relações sociais, se está presente nas interações cotidianas, que espaço é possível para a liberdade?” (p. 321) A resposta que se impõe ao questionamento está vinculada à ideia que poder e liberdade existem "em relação de mútuo incitamento e provocação, no qual cada um se opõe ao outro, mas também no qual cada um é condição para a real existência do outro" (p. 322).

Em outras palavras, reside no plano das subjetividades, ao identificar formas de resistência, ao contestar o poder que reduz sujeitos de direitos a objetos de servidão de práticas (ultra)neoliberais. A libertação aqui delineada se inicia com oposição ferrenha à linguagem do déficit - que mais se assemelha a um novo "pesadelo eugênico" - seguida de um pensamento crítico. Para que não retornemos a "guerra das raças" denunciada por Foucault ${ }^{34}$, é essencial o que Newman entende pela postura do sujeito de direito que afirma a primazia da liberdade, recusa da obediência e da opressão:

[...] o sujeito atribui a si mesmo o direito de questionar a verdade com seus efeitos de poder e de questionar o poder sobre seus discursos de verdade. 'A crítica será a arte de inservidão voluntária, da indocilidade refletida [...]' (grifos do autor, p. 329)

O que a experiência do COVID-19 nos diz sobre deficiência, trabalho e acessibilidade nas cidades? ${ }^{36}$

\section{Considerações finais}

A ideia de ser, estar, "habitar o direito à cidade", introduz-se nessas considerações sob a forma de verbos, que iluminam temática dando-lhe relevância, mais particularmente quando a condição humana encontra-se exposta a uma crise sanitária de proporções inimagináveis.

O presente texto, ensaisticamente organizado, desafia o capacitismo atravessado por elementos que estruturam continuamente os modos de ver e ocultar os corpos das pessoas e seus territórios existenciais ético-estético-políticos. 
Só a descolonização sociocultural possibilita a emergência de novos territórios existenciais de pessoas atribuindo sentidos simbólicos à práxis de ser, estar e habitar uma sociedade em processo de (co)construção, em que sujeitos de direitos reafirmam sua (re)existência.

Nesse sentido, o ensaio optou pela coletivização ao refletir que, o ser, estar e habitar uma cidade se dá ocupando prédios e ruas insuficientemente acessíveis; bloqueando vias de acesso pela via "crip-campiana", fazendo circular corpos ruidosos no centro das cidades como parte de uma "instalação artivista" - de cadeiras de rodas, próteses, órteses -, onde o signo da liberdade da opressão se manifeste. Se nos vêm somente da forma "idealizada", daqui por diante passarão a enxergar "obstáculos políticos" de carne e osso, como (re)existências em que sujeitos de direitos sanitários lutam pela efetividade de políticas públicas anticapacitistas. Logo, as dimensões de acessibilidade e inclusão não são concessões do Estado, mas ora se manifestam sob a forma de questões de princípio das quais não se abre mão em forma de luta e (re)existência.

Em outras palavras, o trecho da poesia anticapacitista da Carmen Callejo "o meu corpo serve a mim”, em tradução livre, é um manifesto para que as cidades/sociedades sejam pensadas por todos e para todas as pessoas que nelas vivem. Logo, pensar sobre ser, estar e habitar é reconhecer o rebelar-se contra ditames (bio)capacitistas, que normatizam o planejamento urbano, usualmente voltado para "corpos perfeitos" que cabem no modus faciendi da arquitetura e engenharia "modernas".

Diz-se que o futuro "reserva surpresas", resta saber que tipo de sociedade "pós-pandêmica" irá se configuar, capacitista ou anticapacitista?

\section{Colaboradores}

AC Amorim e SRCB Gertner conceberam a ideia original do artigo e conduziram o processo de redação. LS Costa e AP Feminella colaboraram, coescreveram, revisaram, comentaram todas as seções do manuscrito.

\section{Referências}

1. Borges SAC. Territórios existenciais ético-estéticos em saúde coletiva. Fractal RevPsicol 2015; 27(2):107-113.

2. Medeiros AP, Rajs S. As Cidades e a Pandemia: efeitos, desafios e transformações. In: Diálogos sobre acessibilidade, inclusão e distanciamento social: Territórios Existenciais na Pandemia, RJ: IdeiaSUS, Fiocruz; 2020. p. 6-9.

3. Union of the Physically Impaired Against Segregation (UPIAS). [cited 2020 jul 15]. Available from: https:// the-ndaca.org/resources/audio-described-gallery/ fundamental-principles-of-disability/

4. Kipen E. En torno a una conceptualización -(im) posible- de la discapacidad. In: Almeida MA, Angelino MA, comp. Debates y perspectivas en torno a la discapacidad en America Latina. Paraná: Universidad Nacional de Entre Ríos; 2012. p. 128-132.

5. Santos BS. Se Deus fosse um ativista dos Direitos Humanos. São Paulo: Cortez Editora; 2013.

6. Santos BS. Direitos humanos, democracia e desenvolvimento. São Paulo: Cortez Editora; 2013b.

7. Bauman Z. Globalização - as consequências humanas. Rio de Janeiro: Zahar; 1999.

8. Gavério M. Nada sobre nós, sem nossos corpos! O local do corpo deficiente nos Disability Studies. Rev Argumentos Montes Claros 2017; 14(1):95-117. 
9. Ribeiro ES, Baptista LAS. Ruídos e silêncios de um corpo na cidade: paradoxos da produção da diferença no contemporâneo. Psicologia Revista 2016; 22(2):374-391.

10. Caiafa J. Comunicação e diferença nas cidades. Lugar comum 2002; 18:91-102.

11. Dias A. Por uma genealogia do capacitismo: da eugenia estatal a narrativa capacitista social. Anais do I Simpósio Internacional de Estudos sobre a DeficiênciaSEDPcD/Diversitas/USP Legal. São Paulo: USP; 2013.

12. Campbell FK. Inciting legal fictions: Disability date with ontology and the ableist body of the law. Griffith Law Review 2001; 10:42-62.

13. Foucault M. As palavras e as coisas. $7^{\mathrm{a}}$ ed. São Paulo: Ed. Martins Fontes; 1995.

14. Amorim AC, Costa LS, Gertner SRCB, Feminella AP, Bernardes V. A linguagem como operadora do déficit na cultura: $\mathrm{O}$ viés capacitista na saúde e educação. Res Society Development 2021; 10(9).

15. Foucault M. Em defesa da sociedade. $4^{\text {a }}$ ed. São Paulo: Ed. Martins Fontes; 2005.

16. Vasconcellos LCF, Oliveira MBH. O sujeito sanitário na perspectiva do direito, p. 27-52, In: MHB Oliveira, LCF Vasconcellos, MC Guilam, GE Schutz, ATMC Silva, organizadores. Direito e Saúde: Cidadania e Ética na Construção de Sujeitos Sanitário. Maceió: Edufal; 2013.

17. Duarte SC. O itinerário da crítica social de Richard Sennett: as relações entre indivíduos e sociedade em perspectiva. Revista do Instituto de Ciências Humanas 2019; 15(23):53-77.

18. Amorim AC, Gertner S, Amorim LA. Cartografia histórico-conceitual da "deficiência": Construção Social feita de "invisibilidades/visibilidades" e de Utopias. In: Uma Ponte ao Mundo - Cartografias Existenciais da Pessoa com Deficiência e o Trabalho. Goiânia: Kelps; 2018.

19. Vallejo C. Estudios críticos latinoamericanos en discapacidad. Capa. Nómadas 2020. [acessado 2021 set 23]. Disponível em: https://bit.ly/3I0Erto

20. Crip Camp. Uma revolução da deficiência. [documentário]. EUA; 2020. [acessado 2020 out 20]. Disponível em: https://encenasaudemental.com/cinema-tv-e-literatura/quando-ocorre-uma-verdadeira-revolucao-pelo -principio-da-inclusao/

21. Convenção sobre os Direitos das Pessoas com Deficiência. Protocolo Facultativo à Convenção sobre os Direitos das Pessoas com Deficiência. Decreto Legislativo $n^{\circ}$ 186, de 09 de julho de 2008. Decreto $n^{\circ} 6.949$, de 25 de agosto de 2009. Declaração Universal dos Direitos Humanos. [acessado 2021 set 23]. Disponível em: http:// www.pcdlegal.com.br/convencaoonu/wp-content/ themes/convencaoonu/downloads/ONU_Cartilha. pdf

22. Brasil. Lei no 13.146. Institui a Lei Brasileira de Inclusão da Pessoa com Deficiência (Estatuto da Pessoa com Deficiência) promulgada em 6 de julho de 2015.

23. Gertner SRCB, Vasconcellos LCF. Trabalho, inclusão e acessibilidade no pós-pandemia: para onde vamos? In: Diálogos sobre acessibilidade, inclusão e distanciamento social: territórios existenciais na pandemia. Rio de Janeiro: IdeiaSUS, Fiocruz; 2020. p. 21-23.
24. Gergen KJ. If persons are texts. Hermeneutics \& Psychological Theory. New Jersey: Rutgers Univ Press; 2007. p. 18-51.

25. Gergen KJ. Therapeutic Professions and the Diffusion of Deficit. J Mind Behavior 1990; 11(3-4), 353-367.

26. Amorim AC. 'O Espetáculo da Loucura' - Alienismo Oitocentista ... Psiquiatria do III Milênio: a Construção social da Linguagem do Déficit e a progressiva enfermidade da Cultura [dissertação]. Rio de Janeiro: Universidade do Estado do Rio de Janeiro; 1997.

27. Ramos F. Do DSM III ao DSM-5: Traçando o percurso médico-industrial da Psiquiatria de Mercado. In: Zorzanelli R, Bezerra Jr. B, Costa JF, organizadores. A Criação de Diagnósticos na Psiquiatria Contemporânea. Rio de Janeiro: Garamond; 2014.

28. Lima RC. O DSM entre a Novilíngua e a Língua Tertii Imperii. In: Zorzanelli R, Bezerra Jr. B, Costa JF, organizadores. A Criação de Diagnósticos na Psiquiatria Contemporânea. Rio de Janeiro: Garamond; 2014.

29. Blikstein I. Kaspar Hauser ou A Fabricação da Realidade. São Paulo: Cultrix; 1995.

30. Lukács G. Para uma ontologia do ser social II. São Paulo: Boitempo Editorial; 2013

31. Avelino N. Introdução: pensar a política com Foucault. In: Avelino N, Vaccaro S, organizadores. O Pensamento Político de Michel Foucault. São Paulo: Intermeios; 2018.

32. Heumann J, Joiner K, Being Heumann. An Unrepentant Memoir of a Disability Rights Activist. EUA, Boston: Ed. Beacon Press; 2020. [cited 2020 out 10]. Available from: https://books.google.com.br/books?i$\mathrm{d}=7 \mathrm{jWaDwAAQBAJ} \&$ printsec $=$ frontcover $\& \mathrm{hl}=\mathrm{p}-$ $\mathrm{t}-\mathrm{BR \#} \mathrm{v}=$ onepage\&q\&f$=$ false

33. Campos SMR, Matiz LCC, editoras. Estudios críticos latinoamericanos en discapacidad. Editorial. Nómadas; 2020:8-9.

34. Foucault M. Microfísica do Poder. 27a ed. São Paulo: Graal; 2013.

35. Newman S. "A crítica como arte da inservidão voluntária”: Foucault, laboétie. In: Avelino N, Vaccaro S, organizadores. O pensamento político de Michel Foucault. São Paulo: Intermeios; 2018.

36. Oliveira B, Navarini D, Aydos V. O que a experiência do Covid-19 nos diz sobre deficiência, trabalho e acessibilidade? Boletim Cientistas Sociais ANPOCS 2020. [acessado 2020 ago 16]. Disponível em: http://anpocs. org/index.php/publicacoes-sp-2056165036/boletimcientistas-sociais/2395-boletim-n-67-cientistas-sociais-e-o-coronavirus A

Artigo apresentado em 31/10/2020

Aprovado em 15/10/2021

Versão final apresentada em 17/10/2021

Editores-chefes: Romeu Gomes, Antônio Augusto Moura da Silva 